\title{
Psychosocial aspects of deliberate physical suicide attempts by children and adolescents
}

\author{
Odeta Kinčinienè ${ }^{1}$, Rokas Šambaras ${ }^{2}$, Augè Lesinskaitė ${ }^{3}$, Virginija Žilinskaitė ${ }^{4}$ and Sigita \\ Lesinskien $\dot{e}^{5}$ \\ 1 Vilnius University, Faculty of Medicine, Institute of Clinical Medicine, Clinic of Childrens' Diseases; \\ odeta.kinciniene@mf.vu.lt \\ 2 Vilnius University, Faculty of Medicine, Institute of Clinical Medicine; rokas.sambaras@gmail.com \\ 3 Vilnius University, Faculty of Medicine, Institute of Clinical Medicine; auge.lesinskaite@santa.lt \\ 4 Vilnius University, Faculty of Medicine, Institute of Clinical Medicine, Clinic of Childrens \\ Diseases; virginija.zilinskaite@mf.vu.lt \\ 5 Vilnius University, Faculty of Medicine, Institute of Clinical Medicine, Clinic of Psychiatry; \\ sigita.lesinskiene@mf.vu.lt \\ * Correspondence: odeta.kinciniene@mf.vu.lt; Tel.: +37069914729
}

\begin{abstract}
Background and objectives: Suicide is a topical issue in Lithuania and all around the world. It is the second most common cause of death among young people. There is a lack of research studies on the psychosocial aspects of adolescent suicide in Lithuania. This study aimed to evaluate demographics, life circumstances, and health conditions as factors related to suicide attempt in adolescents. Materials and Methods: A retrospective study was performed at the Children's Hospital (Vilnius University Santara Clinics). Medical documentation of adolescents treated in this hospital after suicide attempts from January 2011 to April 2018 were analyzed. Results: There were 117 cases of hospitalization due to suicide attempts during this period, and 102 cases were included in the study. There were $83.8 \%$ female and $16.2 \%$ male patients with an average age of $15.02 \pm 1.9$ years ( $p$ $=0.405) ; 40.6 \%$ of patients lived in divorced families, $17.7 \%$ lived in orphanages, $4.2 \%$ lived in foster care, $36.4 \%$ suffered from parental alcoholism, and $17.2 \%$ experienced suicide in their close surroundings. They had comorbidities (girls $72.5 \%$, boys $68.8 \%$ ), mostly depression (31.3\%), were suffering from bullying $(54.1 \%)$ or violence $(26.0 \%)$, and $85.4 \%$ showed signs of other types of selfharm (girls more often $(p<0.001)$ ). Most of them chose to cut for suicide attempts $(86.0 \%$ girls, $56.2 \%$ boys). In $52.8 \%$ of cases, the attempt was spontaneous and $34 \%$ relapsed. Thirty-four events occurred in March (18.9\%) ( $p=0.688)$. Conclusions: Our study revealed the possible circumstances related to adolescent suicide attempt. Female gender was more common overall and males were more likely to carry out more potentially lethal methods. Other common associated factors were a lack of prosperity in family life, experience of bullying, violence, comorbidities, and the early spring period. Signs of any self-harm could be an indicator of later suicide attempt.
\end{abstract}

Keywords: physical suicide attempt; adolescent; self-harm; comorbidities; bullying; violence

\section{Introduction}

Suicides or attempted suicides are problems that are particularly relevant today in Lithuania and all around the world. Based on the data provided by the World Health Organization (WHO), approximately 800,000 people commit suicide annually, and suicide is the second most common cause of death among people aged 15-29 years old globally [1]. The data from the Centre for Disease Prevention and Control of the United States of America indicated the same tendency in 2016, i.e., suicide is the second most common cause of death among people in the 10-24 year age group [2]. The data published by the Organization for Economic Co-operation and Development (OECD) demonstrate that the number of deaths among people aged 10-14 years and 15-24 years has been decreasing; however, the number of suicides, as the causes of death, persists [3]. 
Suicide or attempted suicide is a very pressing problem in Lithuania. Based on data from the Lithuanian Institute of Hygiene (LIH), approximately 1000 people commit suicide annually in Lithuania, and $26.79 \%$ of them belong to the 10-19-year age group [4]. In Lithuania, no studies have been conducted on the psychosocial aspects of deliberate suicide by children and adolescents, despite it being a very current issue. A study carried out in Lithuania in 2010-2015 revealed that suicide makes up a quarter of all deaths in the 10-19 year age group [5].

The most common stage of childhood for suicide attempts is adolescence. The data from a study carried out in the United States of America (USA) in 2015 indicated that the frequency of suicides among adolescents aged 12 to 19 years is almost 50 times higher in comparison with the group aged from 5 to 11 years old [6]. The findings of the study performed in the USA in 2013 indicate that suicidal thoughts in children coincide with the beginning of adolescence, i.e., somewhere between 11 and 13 years of age and continue to 13 to 15 years old, when children increasingly plan suicide or attempt suicide [7]. A study performed in England in 2005 determined that suicides occur less frequently among children aged 15 or younger [8].

Numerous studies have established that suicide attempt is more common among girls. A study carried out in China in 2016 indicated that among scholars and students in the 9-18 year age group, girls had thoughts about suicide more often [9]. Based on data from a study carried out in the USA in 2013, girls, in comparison with boys, had more suicidal thoughts and more frequently carried out suicide attempts. Girls also attempted suicide spontaneously without previously planning it y [7]. Findings in the scientific literature show that girls attempt suicide 3-9 times more often as boys; however, boys commit suicide $2-4$ times more often [10,11]. In a study carried out in 2016 in South Korea, two adolescent groups were compared: those who had attempted suicide and others who had committed suicide. The results indicated that the number of boys in the group of children who committed suicide de facto was higher and the ways in which they did it were of an aggressive kind [12]. A study was carried out in the Czech Republic in 2013 on the seasonal distribution of pediatric suicide. The results indicated that the greatest number of children attempt suicide in March, and the predominant suicide season is spring [13].

Self-harm is pretty common among teenagers in Lithuania as well as in other countries. A study performed in Kaunas in 2009 showed that more than $7.3 \%$ of individuals in Lithuania aged under 20 have tried cutting themselves or have performed other forms of self-harm [14]. According to various studies, approximately $11-20 \%$ of young people deliberately commit acts of self-harm at least once during their lifetime $[10,15]$. The occurrence of such aggressive behavior directed towards oneself, which induces a decision to commit suicide, may be determined by various risk factors. History of at least one previous attempt to commit suicide or self-harm episodes are significant suicide attempt indicators [16]. The WHO identifies several key reasons for attempting suicides as disturbed relationships with other people, divorce or separation, experiencing abuse or violence, conflicts, use of psychoactive substances (alcohol, drugs), mental health problems, chronic diseases, financial constraints, and trauma or a traumatic event (earthquake, terrorist attack, etc.). Social, psychological, and cultural factors create the environment around the individual and this may increase the risk of suicide, and the stigma of suicide, which exists in society, discourages many help-seeking people from finding it [17]. Young people who are admitted to hospitals following suicide attempts often aim to escape their problems, which they cannot face on their own, and they cannot find or do not obtain the required help. These young people strive to show how bad they feel and what kinds of internal conflicts they go through. This is also the way for them to show that they need help. Conflicts with parents or friends and separation from their loved ones are the most difficult things to go through for young people. They are also very sensitive to mockery. To them, suicide seems to be the only possible way out, and after each attempted suicide, the probability that the person will commit suicide increases by 20 times in comparison with people who have not attempted suicide previously [18]. It is also important to mention that each attempt at suicide or suicide itself has a significant impact on people close to that person: relatives, friends, family members, and other persons faced with suicide [19].

This study aimed to analyze the circumstances of life that could be factors related to suicide attempts, and signs or indicators of threatening suicide. 


\section{Materials and Methods}

This cross-sectional retrospective study was performed at the Children's Hospital of Vilnius University Santara Clinics (further, Children's Hospital) from January 2011 to January 2018. Vilnius is the biggest town and the capital city of Lithuania and the Children's Hospital is the biggest tertiary pediatric multidisciplinary clinic in Lithuania too. Case histories were selected according to established, definitive diagnosis codes in the International Classification of Diseases - Australian modification (ICD-10-AM), which is the official method used for Health care system statistics of Lithuania. The study was approved by the Regional Ethics Committee of Vilnius University Hospital (protocol No. 18VVR-6304). Inclusion criteria into the study were the patient's age (under 18), admission to hospital after deliberate suicide physical attempt; health status requiring hospitalization for a living patient; and complete medical documentation. Exclusion criteria were a medical history of unintentional, accidental injuries; deceased patient, lack of indication for hospitalization; and incomplete medical records.

Due to the aim of the study, demographic data: patients age (continuous variable), gender (qualitative variable) were collected from medical histories. Life circumstances data (qualitative variables): family structure, e.g., divorce story (during the suicide attempt the patients lives with only one parent after divorce), living conditions - at home vs. foster care/orphanage were collected from parents and foster carers. Social aspects of life data (qualitative variables): experience of being bullied, violence (experience of physical abuse), parental alcoholism or other addiction, and suicide among close surroundings were collected and evaluated from free form interview conducted by a psychologist. Health conditions (qualitative variables): concomitant disease diagnosed by specialists, were collected and evaluated from case-histories (only those diseases that patients had at the time of the suicide attempt); signs of self-harm were collected and evaluated from medical examination protocols (cuts, burns signs on body, scars left after self-harm). Circumstances of the attempt data (qualitative variables): spontaneous vs. planned decision were collected and evaluated from free form interview conducted by a psychologist; first attempt vs. relapse were collected and evaluated from free form interview conducted by a psychologist; method of suicide (divided into more potentially lethal and less potentially lethal) collected and evaluated from medical examination protocols. The season of attempt were collected from medical histories.

Continuous variables were expressed as the mean \pm standard deviation and qualitative data were reported as numbers and percentages. The normality of the variable distribution was tested by the Kolmogorov-Smirnov test. The significance of differences between groups with a normal distribution of parameters was assessed by the Independent Samples t-test (compared children mean age by gender groups). Associations between qualitative parameters were tested using the $\chi 2$ test or Fisher's exact test. The difference between the observed monthly suicide attempt distribution and expected frequencies was tested using the $\chi 2$ test. The null hypothesis was that the frequency of suicide attempts would be equal for each month. The distribution of family structure was compared with the official data from the Statistical Yearbook of Lithuania showing that $0.5 \%$ of persons under 18 live in orphanages (2). These data were processed using a binomial test (one-sample proportion test). The null hypothesis was that the proportion of children in our study who were living in orphanages is $0.5 \%$. The level of statistical significance was considered to be $p<0.05$. Microsoft Excel 2010 and IBM SPSS 20.0 software were used for statistical data analysis.

\section{Results}

According to the medical code classification during the study period, 117 individuals were hospitalized due to deliberate physical suicide attempts at the Children's' Hospital, and 102 cases met the inclusion criteria and were included into the study and evaluated.

\subsection{Demographic data}

During the study period, 102 cases of intentional suicide attempts were treated in the Hospital. The incidence of the suicide attempts was distributed from three to twenty times per year with the 
maximal quantities occurring in 2014 and 2017. Six patients were hospitalized due to attempting suicide twice, resulting in a total of 96 persons. There were $86(84.3 \%)$ girls' and $16(15.7 \%)$ boys' cases included in the study. The mean age of attempting to commit suicide was $15.02 \pm 1.9$ years (15.12 \pm 1.81 for girls and $14.50 \pm 2.36$ for boys, $p=0.405$ ). The youngest girl at attempt moment was nine, and the youngest boy was eleven years old.

\subsection{Life circumstances}

An analysis of family structure showed that only $37.5 \%$ of children who attempted suicide lived with full families at home, and $40.6 \%$ of them were from divorced families living at home. Through evaluating the life conditions, we revealed that $4.2 \%$ lived in foster care and $17.7 \%$ lived in orphanages. This is in comparison to official data from the Statistical Yearbook of Lithuania (edition 2019) showing that only $0.5 \%$ of persons under 18 live in orphanages. Comparing data from the Statistical Yearbook and our study, we found that living in an orphanage could be a factor related to suicide attempt $(p<0.001)$.

\subsection{Possible social causes of suicide}

From analyzing the medical history, we found that $52(54.1 \%)$ patients who attempted suicide reported being bullied and $25(26.0 \%)$ had experienced violence. Sixteen children $(16.6 \%)$ had experience suicide in their close surroundings and 35 (36.5\%) reported that their parents have an addiction (alcoholism or other) (Figure 1). Comparison of the Official Statistics of Lithuania and our study data on the impacts of these social factors on suicide attempt was impossible due to the lack of data on the incidences of bullying, violence, and parental addiction in our country.

\subsection{Health conditions}

Most of the patients had comorbidities. Concomitant diseases were diagnosed or confirmed by specialists in 69 children (58 (72.5\%) girls and 11 (68.8\%) boys). The most commonly detected comorbidity was a psychiatric disorder $(63 ; 65.6 \%)$ including $25(26.0 \%)$ patients diagnosed with depression. Somatic diseases, such as asthma, diabetes, cerebral palsy, and scoliosis, were diagnosed in nine $(9.4 \%)$ patients. Some patients had more than one comorbidity, for example, asthma with depression, scoliosis with a mixed behavioral and emotional disorder, or cerebral palsy with a mixed behavioral and emotional disorder.

There were $82(85.4 \%)$ patients with signs of previous self-harm, such as scars after cutting or burning in various parts of their body. Girls were found to be significantly more susceptible to selfharm than boys: $73(91.25 \%)$ vs. $9(56.25 \%), p<0.001$, respectively. The frequencies of possible social causes and health conditions in patients after suicide attempts are presented in Figure 1. 
Figure 1. The association of social causes and health conditions related to suicide attempt.

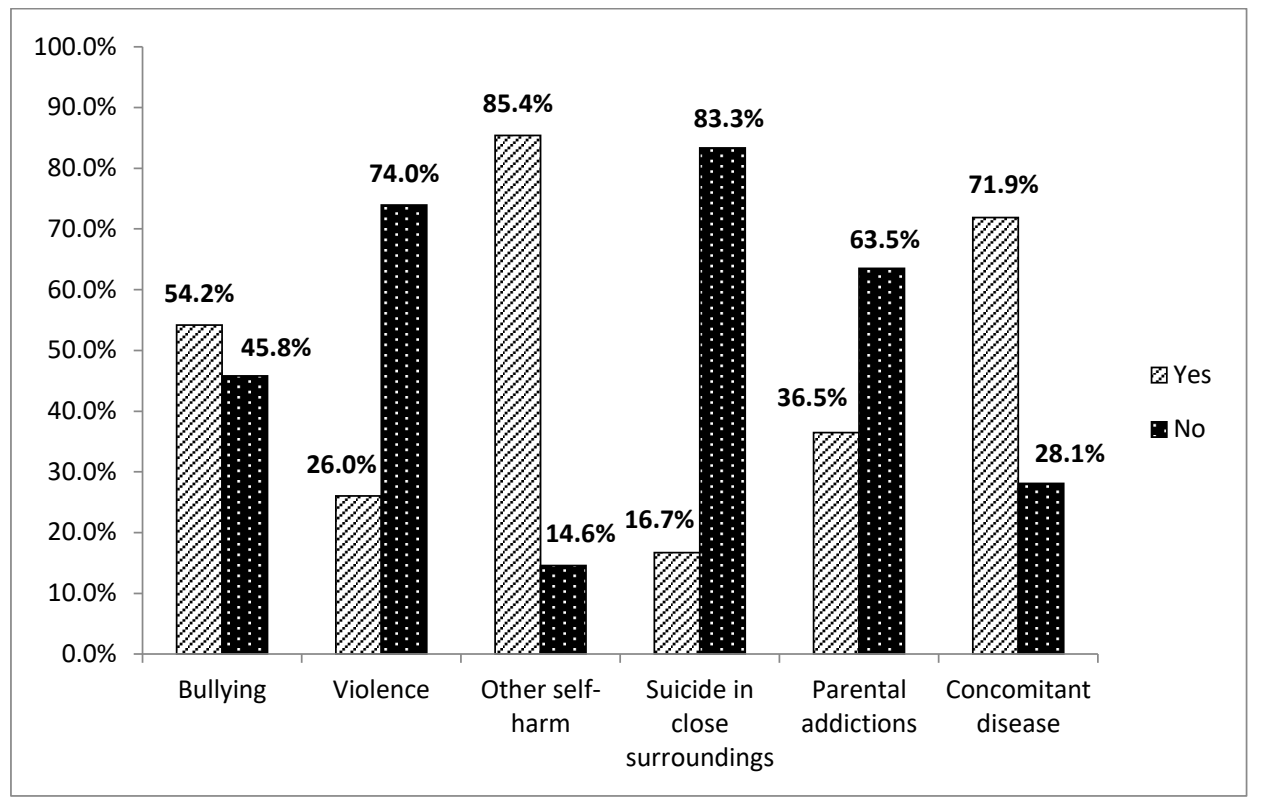

\subsection{Circumstances of attempt}

The distribution of spontaneous and planned suicide cases was almost equal: 54 (52.9\%) were attempted spontaneously, while 48 (47.1\%) were planned. Most of the cases $70(68.6 \%)$ had attempted suicide for the first time, but in 32 cases (31.4\%), suicide had been attempted repeatedly: 26 were on their second attempt, 5 were on their third, and 1 was on their fourth attempt. Differences between the associations of social factors related to suicide attempt relapse presented in Table 1.

Table 1. Association of possible social factors related to suicide attempt relapse.

\begin{tabular}{llll}
\hline The attempt of suicide & $\begin{array}{l}\text { Attempted for the } \\
\text { first time }\end{array}$ & $\begin{array}{l}\text { Attempted } \\
\text { repetitively }\end{array}$ & $p$ \\
\hline $\begin{array}{l}\text { Suicide case } \\
\text { relapse due to }\end{array}$ & $14(87.5 \%)$ & $2(12.5 \%)$ & 0.076 \\
$\begin{array}{l}\text { gender (n-102) } \\
\text { Suicide in the close surroundings }\end{array}$ & $56(65.2 \%)$ & $30(34.8 \%)$ & \\
$\begin{array}{l}\text { Parental addiction } \\
\text { Bullying }\end{array}$ & $9(14.1 \%)$ & $7(21.9 \%)$ & 0.333 \\
Violence & $22(34.4 \%)$ & $13(40.6 \%)$ & 0.549 \\
\hline
\end{tabular}

There were no significant differences between genders on suicide attempt relapse.

By evaluating the methods selected for suicide attempts between girls and boys, we detected that boys are statistically significantly more likely to choose potentially more lethal methods $(p=0.011)$. The most common methods used to commit suicide were cutting of the blood vessels and cutting of the forearms (81.4\%). Detailed information about selected methods of suicide attempts is presented in Table 2. 
Table 2. Methods used for suicide attempt and their distribution by gender.

\begin{tabular}{|c|c|c|c|c|}
\hline \multicolumn{2}{|c|}{ Method of attempt/gender } & \multirow{2}{*}{$\begin{array}{l}\text { Girls } \\
3(3.5 \%)\end{array}$} & \multirow{2}{*}{$\begin{array}{l}\text { Boys } \\
2(12.5 \%)\end{array}$} & \multirow{2}{*}{$\begin{array}{l}\text { Total } \\
5(4.9 \%)\end{array}$} \\
\hline \multirow{6}{*}{$\begin{array}{l}\text { More } \\
\text { potentially } \\
\text { lethal methods }\end{array}$} & $\begin{array}{l}\text { Jumping from a } \\
\text { height }\end{array}$ & & & \\
\hline & Hanging & $4(4.7 \%)$ & $3(18.7 \%)$ & $7(6.8 \%)$ \\
\hline & Strangling & $4(4.7 \%)$ & $1(6.25 \%)$ & $5(4.9 \%)$ \\
\hline & Drowning & $1(1.2 \%)$ & 0 & $1(0.98 \%)$ \\
\hline & Shooting & 0 & $1(6.25 \%)$ & $1(0.98 \%)$ \\
\hline & Total & $12(14 \%)$ & $7(43.8 \%)$ & $19(18.6 \%)$ \\
\hline $\begin{array}{l}\text { Less potentially } \\
\text { lethal method }\end{array}$ & Cutting forearm & $74(86.0 \%)$ & $9(56.2 \%)$ & $\begin{array}{l}83 \\
(81.4 \%)\end{array}$ \\
\hline$p$ & & & & \\
\hline
\end{tabular}

*Comparison of girls' and boys' choices of more and less potentially lethal methods.

Most suicide attempts were performed in March (18.6\%) and February $(10.8 \%)$, with a total of $34.4 \%$ of attempts performed in the early spring period, but there was no significant difference between months $(p=0.688)$. More detailed information is presented in Figure 2.

Figure 2. Monthly and seasonal distribution of suicide attempts.

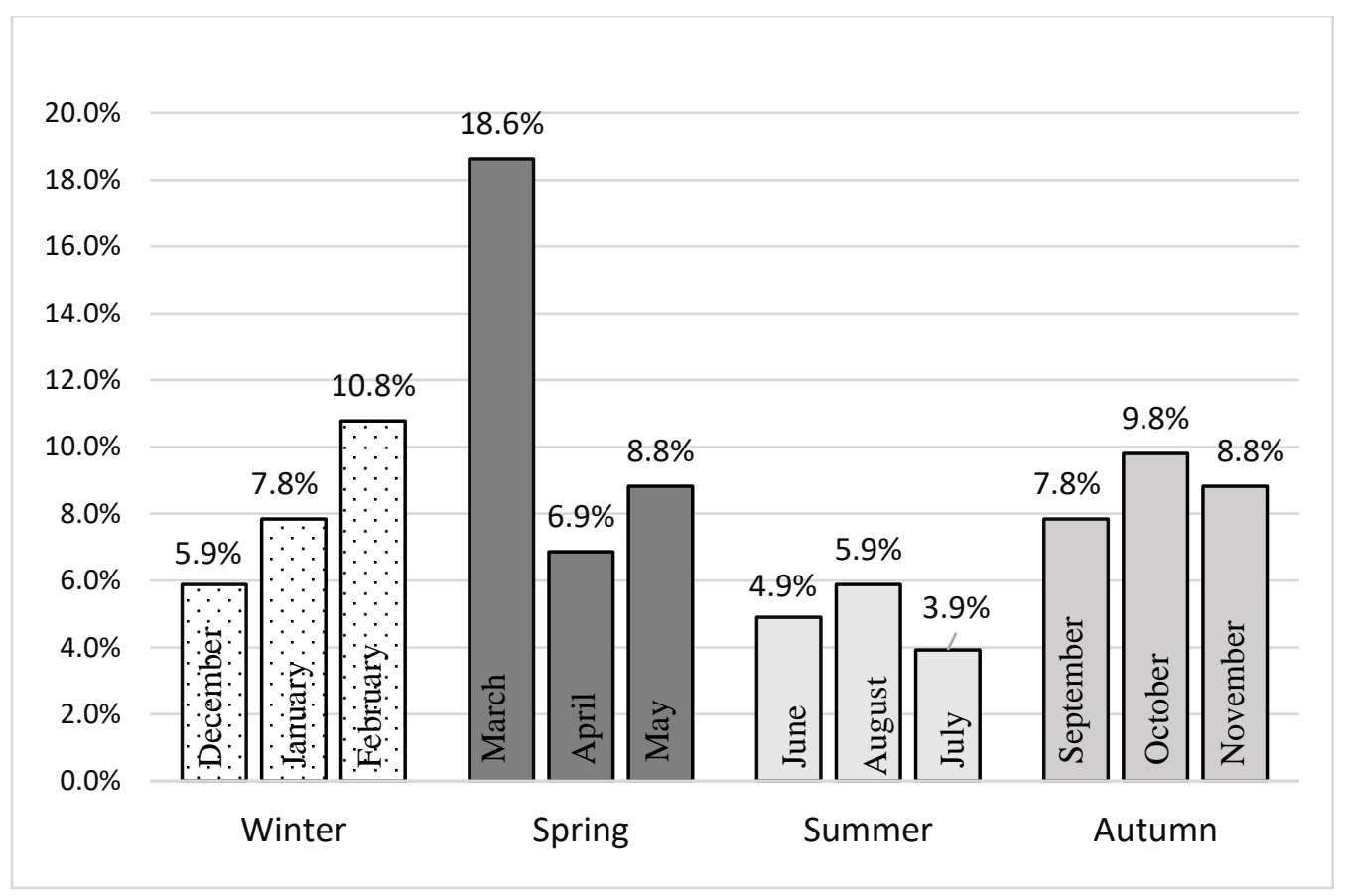

\section{Discussion}

According to the literature review as well as our study results, suicidal attempts in the pediatric population are a very real and sensitive problem. In our pilot study, we tried to evaluate possible factors for young people related to attempts suicide. Our evaluated demographic data detected that the average age of children who attempted suicide was 15.02 \pm 1.9 years. These data are in accordance with data from many other researchers in Europe and the US [6,7,8,20], but differ from data collected by African researchers, where the average age of suicide attempt was found to be 17.5 years [21]. The 
reason why children start to have suicidal thoughts at this age was explained by a study carried out in Singapore in 2015. The study revealed that children start to experience emotional difficulties during adolescence and learn to control them. However, children do not always manage to control strong emotions due to having weak defense mechanisms, and then, by invoking self-harm or attempting suicide, they attempt to let off accumulated emotional surplus, anxiety, anger, or fears [22].

During the study, we established that deliberate suicide attempts were more frequent among girls, and the number of boys attempting suicide was almost four times less. Despite this, boys used potentially more lethal methods to attempt suicide. These results confirm those obtained in other countries. In a study carried out in 2016 in South Korea, results indicated that the number of boys in the group of children who committed suicide was higher and the ways they did it were of an aggressive kind, i.e., by hanging or jumping from high altitudes. There were more girls in the reference group of children who attempted suicide; however, they did not successfully commit suicide, and the most common method used by girls for committing suicide was self-harm by cutting various body parts [12]. During our study, it was found that the most common method chosen to attempt suicide was cutting. More aggressive methods, i.e., attempts to hang or strangle oneself, jump from a high altitude, drown, or shoot oneself were less frequent, but all were more commonly used by boys. Similar data were reported in a few scientific papers [23, 24]. A study carried out in the USA in 2015 established that the most common methods chosen by adolescents for committing suicide were hanging, self-harm (poisoning or cutting), and shooting. This study also disclosed that the frequency of the methods chosen for committing suicide varies depending on the age of the child, e.g., the number of hanging cases proportionally increased with an increase in the age of the child who attempted suicide [20]. Unfortunately, we could not evaluate this because of the small number of cases with more aggressive methods in our group. The children involved in our study most often tried to commit suicide in March and, less frequently, in February. The peak of hospitalizations due to suicidal attempts was spring, with the rate in autumn being slightly lower. The meta-analysis performed in Greece in 2012 revealed that the seasonal character of suicides indicates serotonin's responsibility for mood, and its lowest concentration in blood was detected in early spring. In this season, the amount of sunlight increases, resulting in a drastic increase in the blood serotonin level and therefore an increase in the speed of impulse to commit suicide [25].

By evaluating the living conditions of our study group, we revealed that most of the children who attempted suicide lived with a single parent because their parents were divorced, or, in general, resided outside the family. A considerably lower number of children were living in two-parent families. In a study carried out in the USA in 2013, young people aged from 13 to 18 years were interviewed to assess the spread of suicidal thoughts and plans. It was established that children who lived in single-parent families had suicidal thoughts more often in comparison to those who lived in two-parent families [7]. The research work carried out in the USA in 2010 indicated that the lack of attention from parents and support in the family are key risk factors in determining suicidal thoughts and plans in children [26].

The results of our study confirm data presented by other researchers showing that life in an orphanage or with foster parents is very traumatic for adolescents and is likely to be a cause of suicidal thoughts and attempts. Based on social security data from the Lithuanian Statistics Department, about $0.8 \%$ of all people aged under 18 years in 2016 and $0.5 \%$ in 2019 were living in orphanages in Lithuania [4]. However, our study revealed that suicide attempts were statistically significantly more likely to occur among orphans than among children living in families. This was also confirmed by a meta-analysis performed in England in 2017, where the spread of suicidal ideas, suicide attempts, and suicides committed among adolescents was analyzed. It was determined that the rates of attempted or committed suicides in children residing in an orphanage were 3-4 times higher. There was no difference in the spread of suicidal ideas among children residing in orphanages and children who lived with their parents [27]. The study of adolescents residing in orphanages or living with foster parents carried out in the state of Colorado in the USA in 2014 disclosed that more than $26.4 \%$ of these children had suicide attempts in their medical history, and $4.1 \%$ of attempts were lethal. This study also disclosed that a longer period of residence in an orphanage and more frequent 
changes in place of residence were associated with a greater risk of a child trying to commit suicide [24].

We noticed a tendency for the number of children living in orphanages in Lithuania to decrease, but the problem is still significant. Unfortunately, we could not find data about the incidence of living in foster care among people aged under 18 years in Lithuania. This practice is very "young" in our country and we suggest that the occurrence is less than $4.1 \%$, in contrast to our study group.

During our study, possible social causes and risk factors associated with committing suicide were assessed. Different kinds of humiliation are very common among adolescents living or spending time together as well as during direct contact on internet websites. Our data indicate that more than half of the children who attempted suicide had undergone previous continuous bullying, and about $25 \%$ of these children disclosed that they were the victims of abuse or violence. According to official statistics, about $25 \%$ of school children are victims of bullying, and $3.5 \%$ to $6 \%$ of children experience violence at least once. Based on the data, the incidence of bullying and violence is possibly higher among children and adolescents who attempt suicide. Almost one-fifth of the study group had a previous experience of suicide within their close surroundings and more than one-third had experienced parental alcoholism or another kind of addiction. The main reason given by the children as a cause of suicide was a conflict in the family [28]. A study carried out in the USA in 2001 disclosed that in the prevention of child and adolescent suicides, it is very important to identify suicide risk factors within the domestic environment, such as interpersonal relation issues, family conflict, lack of support, conflict with friends, separations and suicide cases in domestic surroundings [29]. Scientific findings show that children with negative emotional and psychological experiences and emotional dissatisfaction are at a significantly higher risk of committing suicide in comparison with children living within a positive emotional environment [30,31].

Numerous studies have revealed the association of health status with a person's life quality. During our study, it was disclosed that three-quarters of the study group had comorbidities. In most of the cases, comorbidity disease had a psychiatric origin.

Data from an epidemiological study conducted in Lithuania in 2003-2007 showed that $13.1 \%$ of children aged 7-16 have mental health problems according to ICD-10-AM [32]. The results of our study revealed that the incidence of comorbidities, especially psychiatric, is several times more common in children who have attempted suicide. In our study, we found that the most common comorbidity disease among the research subjects was depression, and no less than one-third of all children who attempted suicide suffered from depression. The abovementioned disorders, as established in a study carried out in Germany in 2018, are associated with an increased risk of suicide in both adults and children [33]. A study carried out in the USA in 2015 proposed that 13 to 18 years of age is a critical time frame when depression can develop. There are no comprehensive data on the mechanisms to explain why some children develop depression and some do not; however it is likely that stressful events, e.g., strained interpersonal relations, conflicts with friends, pressure, and genetic predisposition have significant impacts on this. It has also been shown that the reaction of girls to stress originating from interpersonal relations is more intensive and they are exposed to a higher risk of developing depression [34].

After assessing other health conditions in our study group members, we found that no less than three-quarters of the children who attempted suicide had self-harmed themselves cutting or burning various body parts. Based on data found in the scientific literature, children who had suicidal thoughts and attempted suicide often self-harmed themselves [8, 24].

The circumstances of attempts were evaluated with attention paid to the speed of making the decision compared with the recurrence of attempt and choice of method for the attempt. The methods of suicide were discussed earlier, but then assessing the data, we found that more than a half of the children had tried to commit suicide spontaneously and the remaining portion had planned their suicide. Research carried out in Denmark in 2016 disclosed that children, in comparison with adults, more often try to commit suicide spontaneously. This finding was explained by the fact that the understanding of time differs in children compared with adults; therefore, when making decisions, only the current difficulties and short-term consequences of their behavior are considered [35]. Suicide attempt relapse was detected in one-third of our study group. A study carried out in Denmark 
in 2016 identified previous attempts to commit suicide as a key risk factor in determining potential repeated suicide attempts [35]. A review of pediatric suicides performed in the USA in 2019 for a 25 year period analyzed child and adolescent suicides and identified that one-quarter of children who committed suicide had previously attempted to commit suicide [36].

The main limitations of the study are impossibility to evaluate possible factors related to suicide as well related to suicide attempt in adolescents due to lack of those data in the Statistical Yearbook of Lithuania and epidemiological data of the study covering a large party, but not all the country of Lithuania.

\section{Conclusions}

This study is the first to investigate the psychosocial factors of children attempting suicide in Lithuania. Our study observed important circumstances in adolescent suicide attempts. Females were more likely to make an attempt, and males were more likely to choose potentially lethal methods. Other associated factors included a lack of prosperity in family life, experience of bullying and violence, and presence of comorbidities. The critical time for an attempt to occur was found to be early spring. Signs of self-harm could be an indicator before the suicidal attempt.

Considering the relevance of the adolescent suicide issue, intensive and continuous psychiatric/psychological support and care must be given to children who live in an orphanage or are under foster care, have been diagnosed with depression, were or still are bullied, have previously attempted suicide, or repeatedly self-harm themselves by using other methods. Particular attention should be given to these children and adolescents in the late winter and early spring period.

Author Contributions: Conceptualization, Odeta Kinxiniene, Virginija Zilinskaite and Sigita Lesinskiene; Formal analysis, Rokas Sambaras; Investigation, Rokas Sambaras and Auge Lesinskaite; Methodology, Odeta Kinciniene, Virginija Zilinskaite; Supervision, Virginija Zilinskaite; Writing - original draft, Odeta Kinciniene and Auge Lesinskaite; Writing - review \& editing, Odeta Kinciniene and Sigita Lesinskiene.

All authors have read and agreed to the published version of the manuscript.

Funding: This research received no external funding.

Conflicts of Interest: The authors declare no conflict of interest.

\section{References}

1. World Health Organisation, Suicide Prevention. https://www.who.int/health-topics/suicide\#tab=tab 2/ Accessed 20 September 2019.

2. Suicide Mortality in the United States, 1999-2017. (2018) https://www.cdc.gov/nchs/data/databriefs/db330h.pdf Accessed 13 July 2019.

3. Health at a Glance: Europe 2018 STATE OF HEALTH IN THE EU CYCLE. (2018) https://ec.europa.eu/health/sites/health/files/state/docs/2018 healthatglance rep en.pdf/ Accessed 18 August 2019.

4. Institute of Hygiene of Lithuania. Couse of death. http://www.hi.lt/lt/mpr-statistine-informacija.html/ Accessed 21 May 2019.

5. Lekecinskaite, L.; Lesinskiene, S. Suicides of children and young adults under 20 in Lithuania in 2010-2015. Public Health, 2017, 2(77), 74-80.

6. Bridge, J.A.; Asti, L.; Horowitz, L.M.; Greenhouse, J.B.; Fontanella, C.A., Sheftall, A.H., Kelleher, K.J., Campo, J.V. Suicide Trends Among Elementary School-Aged Children in the United States From 1993 to 2012. JAMA Pediatrics, 2015, 169(7), 673-677.

7. Nock, M.K.; Green, J.G.; Hwang, I.; McLaughlin, K.A.; Sampson, N.A.; Zaslavsky, A. M.; Kessler, R. C. Prevalence, Correlates, and Treatment of Lifetime Suicidal Behavior Among Adolescents. JAMA Psychiatry, 2013, 70(3), 300.

8. Hawton, K.; James, A. Suicide and deliberate self-harm in young people. BMJ, 2005, 330(7496), 891-894.

9. Tan, L.; Xia, T.; Reece, C. Social and individual risk factors for suicide ideation among Chinese children and adolescents: A multilevel analysis. International Journal of Psychology, 2016, 53(2), 117-125. 
10. Klonsky, E.D.; Victor, S.E.; Saffer, B.Y. Nonsuicidal Self-Injury: What We Know, and What We Need to Know. The Canadian Journal of Psychiatry, 2014, 59(11), 565-568.

11. Kaess, M.; Parzer, P.; Haffner, J.; Steen, R.; Roos, J.; Klett, M.; ... Resch, F. Explaining gender differences in non-fatal suicidal behaviour among adolescents: a population-based study. BMC Public Health, 2011, 11(1):1-7.

12. Joo, S.H.; Wang, S.M.; Kim, T.W.; Seo, H.J.; Jeong, J.H.; Han, J.H.; Hong, S.C. Factors associated with suicide completion: A comparison between suicide attempters and completers. Asia-Pacific Psychiatry, 2015, 8(1), $80-86$.

13. Zakharov, S.; Navratil, T.; Pelclova, D. Suicide attempts by deliberate self-poisoning in children and adolescents. Psychiatry Research, 2013, 210(1), 302-307.

14. Laskyte, A.; Zemaitiene, N. The Types of deliberate self-harm and its prevalence among Lithuanian teenagers. Medicina, 2009, 45(2), 132-139.

15. Ross, S.; Heath, N. A Study of the Frequency of Self-Mutilation in a Community Sample of Adolescents. Journal of Youth and Adolescence, 2002, 31(1), 67-77.

16. Shain, B. N. Youth Suicide: The First Suicide Attempt. Journal of the American Academy of Child \& Adolescent Psychiatry, 2018, 57(10), 730-732.

17. World Health Organisation. Suicide. (2019). https://www.who.int/news-room/fact-sheets/detail/suicide, Accessed 22 September 2019.

18. Jans, T.; Taneli, Y.; Warnke, A. Suicide, and Self - Harming Behaviour. IACAPAP E-textbook Child Adolesc Ment. Heal. Geneva Int. Assoc. Child. Adolesc. Psychiatry Allied. Prof., 2012, 1-35.

19. World Health Organization. Practice manual for establishing and maintaining surveillance systems for suicide attempts and self-harm. (2016). World Health Organisation Document Production Services, Geneva, Switzerland.

20. Sullivan, E.M.; Annest, J.L.; Simon, T.R.; Luo, F.; Dahlberg, L.L. (2015). Suicide Trends Among Persons Aged 10-24 Years - United States, 1994-2012. MMWR Morbidity and Mortality Weekly Report, 2015, 64(08), 201-205.

21. Darré, T.; Consuela, K.A.C.; Saka, B.; Djiwa, T.; Ekouévi, K.D.; Napo-Koura, G. Suicidal ideation and suicide attempts in subjects aged 15-19 in Lomé (Togo). BMC Research Notes, 2019, 12(1).

22. Lauw, M.; How, C.H.; Loh, C. Deliberate self-harm in adolescents. Practice Integration and Lifelong Learning, 56(6), 2015, 306-309.

23. Hawton, K.; Saunders, K.E.; O'Connor, R.C. Self-harm and suicide in adolescents. The Lancet, 2012, 379(9834), 2373-2382.

24. Taussig, H.N.; Harpin, S.B.; Maguire, S.A. Suicidality Among Preadolescent Maltreated Children in Foster Care. Child Maltreatment, 2014, 19(1), 17-26.

25. Christodoulou, C.; Douzenis, A.; Papadopoulos, F. C.; Papadopoulou, A.; Bouras, G.; Gournellis, R.; Lykouras, L. Suicide and seasonality. Acta Psychiatrica Scandinavica, 2011, 125(2), 127-146.

26. Gardner, W.; Klima, J.; Chisolm, D.; Feehan, H.; Bridge, J.; Campo, J.; ... Kelleher, K. Screening, Triage, and Referral of Patients Who Report Suicidal Thought During a Primary Care Visit. Pediatrics, 2010, 125(5), 945-952.

27. Evans, R.; White, J.; Turley, R.; Slater, T.; Morgan, H.; Strange, H.; Scourfield, J. Comparison of suicidal ideation, suicide attempt and suicide in children and young people in care and non-care populations: Systematic review and meta-analysis of prevalence. Children and Youth Services Review, 2017, 82, 122-129.

28. Wisqars (Web-based Injury Statistics Query and Reporting System) Injury Center CDC. https://www.cdc.gov/injury/wisqars/LeadingCauses.html /Accessed 18 December 2019.

29. Pfeffer, C.R. Diagnosis of childhood and adolescent suicidal behavior: unmet needs for suicide prevention. Biological Psychiatry, 2001, 49(12), 1055-1061.

30. Johnson, J.G.; Cohen, P.; Gould, M.S.; Kasen, S.; Brown, J.; Brook, J.S. Childhood Adversities, Interpersonal Difficulties, and Risk for Suicide Attempts During Late Adolescence and Early Adulthood. Archives of General Psychiatry, 2002, 59(8), 741.

31. Thompson, R.; Proctor, L.J.; English, D.J.; Dubowitz, H.; Narasimhan, S.; Everson, M.D. Suicidal ideation in adolescence: Examining the role of recent adverse experiences. Journal of Adolescence, 2012, 35(1), 175186.

32. Lesinskiene, S.; Girdzijauskiene, S.; Gintiliene, G.; Butkiene, D.; Puras, D.; Goodman, R.; Heiervang, E. Epidemiological study of child and adolescent psychiatric disorders in Lithuania. BMC Public Health, 2018, 18(1). 
33. Becker, K.; Schmidtke, A.; Glasow, N. Suizidpraventive Architektur in der Kinder - und Jungendpsychiatrie. Zeitschrift fur kinder - und Jungendpsychiatrie und psychotherapie, 2018, 1-8.

34. Hankin, B.L.; Young, J.F.; Abela, J.R.Z.; Smolen, A.; Jenness, J.L; Gulley, L.D.; ... Oppenheimer, C.W. Depression from childhood into late adolescence: Influence of gender, development, genetic susceptibility, and peer stress. Journal of Abnormal Psychology, 2015, 124(4), 803-816.

35. Hedeland, R.L.; Teilmann, G.; Jørgensen, M.H.; Thiesen, L.R.; Andersen, J. Risk factors and characteristics of suicide attempts among 381 suicidal adolescents. Acta Paediatrica, 2016, 105(10), 1231-1238.

36. Molina, D.K.; Farley, N. J. A 25-Year Review of Pediatric Suicides. The American Journal of Forensic Medicine and Pathology, 2019, 40(3), 220-226. 